\title{
Population dynamics of white grubs (Coleoptera: Scarabaeidae) in the rose environment of Northern Bangalore, India \\ S. Kumar ${ }^{\mathrm{a}}$, M. Sankar, V. Sethuraman ${ }^{\mathrm{a}}$ and A. Musthak \\ University of Agricultural Science, G.K.V.K. Campus, Hebbal, Bangalore, Karnataka-560 024, India. \\ ${ }^{a}$ Multiplex Biotech Pvt. Ltd., KHT Complex, Andarasanahalli, Tumkur, Karnataka-572 016. \\ kumars@gmail.com, shankar_ms10@yahoo.com, sethuramanbio@gmail.com,musthakali@rediffmail.com
}

\begin{abstract}
Faunal composition of scarabaeids associated with rose cultivation in Bangalore districts of Karnataka (India) was investigated. During the field survey, thirteen species of scarabaeid beetles belonging to nine genera representing three sub families: Melolonthinae, Rutelinae, and Cetoniinae were recorded. Maximum of five species belong to subfamily Melolonthinae and each three species belong to Rutelinae, and Cetoniinae. Among the identified species, Holotrichia seerata, Schizonycha ruficollis, Anomala bengalensis, and Adoretus versutus were found to be the most dominant leaf feeders and Maladera sp. and Apogonia ferruginea was found to be infesting more on flowers on rose. The scarabaeids adults' emergence began after the $1^{\text {st }}$ rain in April and it was continued up to the last week of September in Bangalore condition. Maximum numbers of adults were recorded between 19.00 and $19.30 \mathrm{hrs}$ and thereafter no emergence/ a little emergence was noticed from each species of scarabaeids. The degree of leaf damage caused by $H$. seerata, $S$. ruficollis, and $A$. versutus were significantly more on rose leaf irrespective of presence or absence of flowers. The outcome of the study may be helpful in pest management especially of rose plantation.
\end{abstract}

Keywords: Beetles, rose, floriculture, pest management.

Introduction

Rose (Rosa spp.) belongs to the family Rosaceae, which comprises of 120 species and 20000 cultivars. It is generally regarded as the queen of flowers because of its fragrance, varied colors, architecture, and the sizes. Roses are grown commercially in greenhouses and outdoor nurseries, where field-grown cut flowers, potted miniature roses, bare-root roses for use in landscapes, and potted roses for the garden-center trade are produced. Although several species of roses are native to the state, the rose industry is based primarily on the many exotic rose hybrids available, including antique and shrub roses.

In India, rose is grown in 5498 hectares and in Karnataka alone it is being cultivated around 1465 ha. with annual production of 3817 tonnes. Rose stands first in the world cut flowers (Gowda et al., 1984). The cultivation of cut flowers in India under green house has increased from few hectares during $1979-80$ and it was grown upto 300 ha. during 1994-95. Maximum floriculture industry is concentrated in Bangalore, Pune, Hyderabad, Nasik and Trivandrum (Gowda \& Jayaprasad, 1997). Many species of insects and mites attack and injure roses. Under certain conditions, roses become particularly susceptible to certain pests. Among the insect pests in rose, the rose chafers (Scarabaeidae) cause considerable damages by feeding on both leaves and flowers. Majority of the beetles is nocturnal; some are diurnal and found to be feeding on leaves and flowers. Adult activity above the ground is of short period only for the purpose of mating and feeding, while the rest of its life spent inside the soil. Information on their behavior and extent of damage to roses is scanty. A very little information is available on the management on rose pests. Information on their control is restricted to the use of insecticides with limited success. Under this circumstance, we proposed to undertake a detailed study on the behavior, distribution pattern, and faunal composition of scarabaeids associated with roses cultivating in Bangalore districts of Karnataka (India).

\section{Materials and methods}

To study the faunal composition of scarabaeids in rose plants was under taken from April 2004 to March 2005 in Northern Bangalore district of Karnataka (India) at five locations; Lalbagh, K.K.V.K., Hoskote, Doddaballapur and Nelamangala. The beetles were collected between 18.30 to $24.00 \mathrm{~h}$ using a powerful flash light. Fifteen rose plants were selected at random in each rose garden in all the localities of surveyed. Adult beetles were collected during the peak emergence months of April - May followed by weekly observation during the entire monsoon (pre and post monsoon). All the scarabaeids collected in rose plants at various locations were brought into the laboratory with help of plastic containers (enclosed with perforated lid) and they were sorted out by species level to compile a faunal list of rose chafers. All the adults were collected in the fields preserved in $80 \%$ ethyl alcohol for further detailed studies. Data on the population density of scarabaeids and degree of damage caused by beetles on rose are compelled based from the collected data. The data were obtained during the studies were normalized by square root transformation. The significance of differences was 
Table1. Fauna of Scarabaeids recorded on rose during April 2004- March 2005 around Bangalore district.

\begin{tabular}{|c|c|c|c|c|}
\hline Sub family & Species recorded & Plant preferred & Plat part affected & Location \\
\hline \multirow[t]{7}{*}{ Melolonthinae } & Holotrichia seerata & $\begin{array}{l}\text { Rose, Neem and } \\
\text { Tamarind }\end{array}$ & $\begin{array}{l}\text { Leaves }+++ \\
\text { Flower }+\end{array}$ & $\mathrm{G}, \mathrm{D}, \mathrm{H}, \mathrm{L}$ \\
\hline & Holotrichia reynaudi & Rose and apple & Leaves + & G, L \\
\hline & Holotrichia rufoflava & Rose and Albegia & Leaves + & $\mathrm{G}$ \\
\hline & Schizonycha ruficollis & $\begin{array}{l}\text { Rose, Neem and } \\
\text { Tamarind }\end{array}$ & Leaves +++ & $\mathrm{G}, \mathrm{L}, \mathrm{D}, \mathrm{H}, \mathrm{N}$ \\
\hline & Apogonia ferruginea & Rose and Guava & Leaves + \& flower ++ & $\mathrm{G}, \mathrm{L}, \mathrm{D}, \mathrm{H}, \mathrm{N}$ \\
\hline & Apogonia rauca & Rose and Guava & Leaves + \& Flower ++ & $\mathrm{G}, \mathrm{L}, \mathrm{H}$ \\
\hline & Maladera sp. & Rose & Leaves +++ & $\mathrm{G}, \mathrm{L}, \mathrm{H}, \mathrm{D}, \mathrm{N}$ \\
\hline \multirow[t]{3}{*}{ Rutelinae } & Anomala bengalensis & Rose and Guava & $\begin{array}{l}\text { Leaves }+\& \\
\text { Flower }+++\end{array}$ & G, L, H, D. N \\
\hline & Adoretus versutus & Rose & Leaves +++ & G, L \\
\hline & Adoretus bicolor & Rose and Grape & Leaves ++ & G, L, D. H \\
\hline \multirow[t]{3}{*}{ Cetoniinae } & Heterorrhina elegans & Rose and Mango & Flower + & G \\
\hline & Oxycetonia versicolor & Rose and Brinjal & Flower + & $G, L, D$ \\
\hline & Protaetia cinarea & Rose and Brinjal & Flower + & G, D \\
\hline
\end{tabular}

Extent of damage level: + = slight/low level; $++=$ Moderate; +++ severe/high level.

determined by analysis of variance (ANOVA) at the level of C.D. $=5 \%$.

Among the identified scarabaeid species during the survey, six dominant species of $H$. seerata, $A$. bengalensis, $S$. ruficollis, $A$. versutus, Maladera sp., and $A$. ferruginea was individually tested to check the degree of leaf damage on rose plants. Individual species of the beetles collected during the night using plastic jars containing soil where appropriate moisture. Fresh rose twigs with known leaf area (using graphs sheet method) was kept in the jar $(16 \times 20 \mathrm{~cm})$ as a feed for beetles and released one healthy and active adult of each male and female. Each species was used separate jar and all the jars closed with suitable perforated lid. Each treatment replicated five times and the experiment repeated two times to confirm the results. An observation made on the degree of leaf feeding caused by different species of scarabaeids on rose by using the following formula.

Area given for feeding - area left after feeding Degree of feeding $=$ $\mathrm{X} 100$

\section{Results}

$$
\text { Area given for feeding }
$$

\section{Faunal composition of scarabaeids on rose}

A systematic survey conducted in the study on faunal composition of scarabaeids damaging rose plants a total of thirteen species were recorded belonging to three subfamilies Melolonthinae (7genera), Rutelinae (3-genera) and Cetoniinae (3genera) (Table1).

1) Subfamily: Melolonthinae

i) Holotrichia seerata Fabricius. The beetles is reddish to blackish red or dark tan in color measuring about two $\mathrm{cm}$. in length and one $\mathrm{cm}$ in breadth. Males are slightly smaller than female. The pygidium of the female slightly exposed beyond elytra. Antennae are tem segmented and the three apical lobes form the lamellate club. The labrum is chitinous and is visible externally. The front tibiae are tridentating. The prothorax serrated at the sides. The elytra are punctuated and striate. This species collected from all the five locations surveyed around Bangalore causing considerable damages on rose by feeding both flowers and foliage. The extent of damage caused on leaves significantly higher than flowers. This species invariably found to congregate on plants near the borders in a field. The beetles were in clumps maximum of $40-60$ numbers/ plant and the clumps were restricted to a single branch on a plant. This species recorded from April upto the last week of May. The beetles were found to be infesting on the other host plants, such as; tamarind and neem.

ii) $H$. rufoflava Brenske become more shining and lighter in colored when compared to $H$. seerata and $H$. reynaudi. The body enlarged measuring 18-22 $\mathrm{mm}$ in length, 8-10 $\mathrm{mm}$ in breadth. The punctuations on clypeus and head are closer and deeper. Individuals of this species were collected only at G.K.V.K. The beetles were also found to be feeding on leaves of Albizzia sp.

iii) Holotrichia reynaudi Blanchard the beetles look like $H$. seerata in form and color but differ in size and paramera. The pronotal margin is not serrated. Body length is $16-18 \mathrm{~mm}$. Black form of this species was collected from G.K.V.K. and Lalbagh. It was found feeding on the leaves of rose plants and few individuals were found on the flowers. 
They were also found feeding on rose, apple and drumstick leaves (Table 1).

iv) Schizonycha ruficollis Fab. is shining rufocastaneous; clypeus emarginated; upper surface of the head roughly rugose; $3^{\text {rd }}$ antennal segment beaded; club in male is long, larger then $2^{\text {nd }}$ to $7^{\text {th }}$ segment; punctuation on the elytra closer and irregular; forelegs long, tarsus more than twice as long as tibia, close forked at the tip. The elongated body has $12-13 \mathrm{~mm}$ in length. This species was very common in all the locations surveyed. The beetles were found in large numbers after the April rains. They feed on the leaves by clinging to the leaf from the margin. Few beetles were found feeding on flower while a large majority feed on the leaves of rose, leaving only midrib and veins. Among the scarabaeids beetle studies, this species caused maximum damage to the rose plants and also found feeding on tamarind and neem leaves in large numbers near the rose gardens.

v) Apogonia ferruginea (F.): Individuals of this species are shining, light brown in color with close and deep punctuations; underside of the abdomen pubescent; clypeus emarginated extending across the compound eyes; head broader than long, oval. Elytra elevated along the suture. The body is 5-6 $\mathrm{mm}$ length. These beetles were distributed throughout Bangalore districts and this species was one of the lowest numbers of melolonthid beetles recorded during the study. Maximum adults were found feeding on flowers, leaves of rose plants and few of them were found to be feeding on guava leaves adjacent to rose garden. Emergence of these beetles started during the $2^{\text {nd }}$ week of April and continued till the $2^{\text {nd }}$ week of August. The peak emergence observed in the month of April-May.

vi) Apogonia rauca (F.): Adult of this species is similar to $A$. ferruginea in structure, but easily separable due to its coloration and size. The beetle is large and stoutly built, $7-8 \mathrm{~mm}$ in length with shining dark brown coloration. This species of adults were collected from G.K.V.K., Lalbagh and Hoskote. It feeds more extensively on rose flowers than leaves. This species appeared in small numbers starting from the month of April and continued until the middle of August with a break during the month of June.

vii) Maladera spp.: The adult is oval shining presents a velvety appearance with crimson dark to cherry colouration. Labrum connate, clypeus roughly rugose, upper surface of head smooth, antennae 11 segmented. $3^{\text {rd }}$ segment bead like, segments 4 to 8 serrated; elytra with longitudinal parallel striations and irregular punctuations. Hind tibia is broad and flattened. Body length is $4-6 \mathrm{~mm}$. Adults were found to be active from April to December. Large number of beetles emerged after

\section{http://www.indjst.org}

Vol.2 No 1 (Jan. 2009)

$1^{\text {st }}$ summer rains and maximum number of adults were found to be on rose buds by making small holes. In case of unopened flowers, it feeds on the petals. This was one of the common species found in all the rose gardens surveyed.

2) Subfamily: Rutelinae

i) Anomala bengalensis Blachard: Moderately elongate pale lestaceous yellow head, the hind tibiae and all the tarsi dark. The head is rather finely punctaterugose, the clypeus broadly and transversely rectangular, its front margin strongly reflexed. The pronotum is strongly rounded, the front tibia is tridentate and the larger claw of the front and middle teeth cleft. Body size is $19-22 \mathrm{~mm}$ in length and $10-11 \mathrm{~mm}$ in breadth. This species was collected from all the five locations surveyed. It was causing considerable damage to rose by feeding both on leaves and flowers, the extent of damage to flowers was high as compared to leaves. Adults were found feeding on opened flower in larger numbers (2-18 beetles/flower) and the clumps were uniformly distributed throughout the field. Large number of these were found emerging from the last week of April and it was continued for nearly one month till the end of May. Emergence of beetles was completely seized after last week of May even though there was continous rain in the later part of the season. It was also found feeding on guava flowers at G.K.V.K. and Lalbagh.

ii) Adoretus versutus Harold: Reddish chestnut, with the forehead and pronotum, except the sides of the latter and sometimes a median line, dark and evenly, but not very densely clothed with grey decumbent setae. It is moderately broad and convex, the clypeus is coarsely rugose, and the front tibiae armed with three strong acute teeth. In male, the eyes are large and the clypeus small and transverse. The protonum is less convex than in the female and rather less shining. In female, the body is broader, more convex, and generally larger than in the male measuring $9-12 \mathrm{~mm}$ in length and $5-6 \mathrm{~mm}$ in breadth. This species of adults was found to be more in numbers throughout the season from April to September at G.K.V.K. and Lalbagh. It causes extensive damage by feeding on leaves. The damage symptoms by this species are characterized by presence of irregular holes on the entire leaf lamina. Occasionally, very few beetles were also found on the flowers.

iii) Adoretus bicolor Brenske: Bright reddish yellow with the pronotum reddish and the head and tarsi rather deep red; closely clothed above and beneath with minute uniform decumbent setae. In male, the clypeus is smaller than that of the female. The body containing $10-11 \mathrm{~mm}$ length and 5-6 $\mathrm{mm}$ breadth. This species was active from $2^{\text {nd }}$ fortnight of April to August with a peak emergence 
in the month of April-May. The damage symptom of this species is almost similar to that of $A$. versutus, but they appear in less numbers on rose. However, large population of this species was found feeding on grape leaves in the vicinity of rose gardens both at G.K.V.K., and Doddaballapur (Table1).

3) Subfamily: Cetoniinae

i) Oxycetonia versicolor Fabricius: The beetle is compact and oval. Measuring about $15 \mathrm{~mm}$ in length and $7 \mathrm{~mm}$ in breadth. Its upper surface is smooth. The prothorax and elytra are brick red in colour. A pair of black spots are present on the prothorax and lateral margins reveal white border. The elytra bear various patterns of white spots. The front tibiae tridentate and all the femora fringed with yellow hairs. Both sexes are alike. This species was noticed from July to October. It was collected maximum number from G.K.V.K., Lalbagh and Doddaballapur feeding on rose flowers in the morning hours. A substantial numbers were found feeding on brinjal plants adjacent to rose garden.

ii) Heterorrhina elegans Var.: The beetle has an elongate body. It measures about $16 \mathrm{~mm}$ in length and $7 \mathrm{~mm}$ in breadth. It is bright metallic green in color and closed with yellow hairs above and beneath. Clypeus is narrow with a middle carinate line. Eyes are prominent. The front tibiae are tridentating. The two terminal teeth of the front tibiae in male are longer than the female. The terminal spines of elytra are prominent in males as compared to females. Like the other members of Cetoniinae, this species also found feeding on rose flowers during the early hours of the day. The beetles were noticed from June to October on rose flowers at G.K.V.K. The damage caused by this species on rose was very negligible. iii) Protaetia cinarea Kirby: The beetles look like $O$. versicolor in general; appearance, grayish in color with white patches on elytra and the body measure about $13 \mathrm{~mm}$ in length and 5-6 $\mathrm{mm}$ in breadth. This beetle found in small numbers on rose during June-Sep feeding on rose flowers both during the daytime and evening hours. Large numbers of beetles were feeding on brinjal plants in the near proximity of rose gardens.

Incidence of different species of scarabaeids caused on rose plant

Among the 13 species of scarabaeid beetles recorded on rose eleven species were found to feed extensively both on leaves and flowers causing economic damages to rose plants (Table 2) and the other two species such as; $H$. rufoflava http://www.indjst.org

Vol.2 No 1 (Jan. 2009) and $H$. reynaudi were failed to feed on rose either flowers or leaves in the laboratory. Among the leaf feeders, the percent incidence caused by $S$. ruficollis was significantly more in all the three locations, i.e. G.K.V.K. (28.83\%), Doddaballapur $(21.98 \%)$ and Lalbagh $(29.40 \%)$ than the other species. The percent incidence caused by $A$. versutus was recorded the second most dominant species collected from G.K.V.K., Doddaballapur and Lalbagh (14.68, 19.29 and $16.80 \%$ respectively). Among the flower feeder, Maladera sp. was found to be dominant in all the 3 locations, G.K.V.K. (12.22 \%), Doddaballapur (14.62 \%), and Lalbagh (15.01\%). However, from the pooled data, of the species $S$. ruficollis, $A$. versutus, and Maladera sp. accounted for 27.84, 16.92, and $10.61 \%$ respectively. Among the flower feeder's subfamily cetoniinae, the percent incidence caused by Protaetia cinarea, Oxycetonia versicolor and $\mathrm{H}$. elegans accounted for 2.24, 2.08, and $1.71 \%$ respectively in the above said three locations. The population of cetoniids in all the locations was significantly low (Table 2).

Degree of leaf damage in absence and presence of flower

The relative consumption of rose leaves in absence of flower under laboratory condition by six species of scarabaeids indicates that there was

Table 2. Population densities (\%) of different species of scarabaeid beetles on rose at various locations recorded during April 2004 to March 2005.

\begin{tabular}{|l|c|c|c|c|}
\hline Species & GKVK & $\begin{array}{l}\text { Doddaball- } \\
\text { apur }\end{array}$ & Lalbagh & $\begin{array}{l}\text { Pooled } \\
\text { abundance }\end{array}$ \\
\hline Melolonthinae & 8.16 & 8.27 & 8.66 & 8.14 \\
\hline $\begin{array}{l}\text { Holotrichia } \\
\text { seerata }\end{array}$ & 8.16 & 21.98 & 29.40 & 27.84 \\
\hline $\begin{array}{l}\text { Schizonycha } \\
\text { ruficollis }\end{array}$ & 28.83 & 6.25 & 5.36 & 6.47 \\
\hline $\begin{array}{l}\text { Apogonia } \\
\text { ferruginea }\end{array}$ & 4.82 & 0.0 & 3.13 & 5.86 \\
\hline $\begin{array}{l}\text { Apogonia } \\
\text { rauca }\end{array}$ & 12.22 & 14.62 & 15.01 & 10.61 \\
\hline Maladera sp. & 10.99 & 12.53 & 6.52 & 10.01 \\
\hline $\begin{array}{l}\text { Rutelinae } \\
\text { Anomala } \\
\text { bengalensis }\end{array}$ & 14.68 & 19.29 & 16.80 & 16.92 \\
\hline $\begin{array}{l}\text { Adoretus } \\
\text { versutus }\end{array}$ & 5.61 & 8.17 & 6.79 & 6.86 \\
\hline $\begin{array}{l}\text { Adoretus } \\
\text { bicolor }\end{array}$ & 2.15 & 2.99 & 0.0 & 1.71 \\
\hline $\begin{array}{l}\text { Cetoniinae } \\
\text { Heterorrhina } \\
\text { elegans }\end{array}$ & 0.92 & 2.72 & 2.59 & 2.08 \\
\hline $\begin{array}{l}\text { Oxycetonia } \\
\text { versicolor }\end{array}$ & 1.31 & 2.99 & 2.41 & 2.24 \\
\hline $\begin{array}{l}\text { Protaetia } \\
\text { cinarea }\end{array}$ & & & \\
\hline
\end{tabular}


significant difference in actual leaf consumption by two species of beetles, i.e. $H$. seerata and $A$. bengalensis. However, $H$. seerata caused significantly more percent leaf area damage (36.70 $\%$ ) followed by $A$. bengalensis (22.51\%) however, the damages caused by $S$. ruficollis and $A$. versutus was on par with each other (11.08 and $11.98 \%$ respectively). The beetles belong to the genera Maladera sp. was found to cause least damage $(3.43 \%)$ than all other species on rose leaves. However, percent leaf area damage caused by $A$. ferruginea $(7.17 \%)$ did not differ statistically from that damages caused by Maladera sp., S. ruficollis and $A$. versutus. Total of the six species of scarabaeids tested, $H$. seerata caused higher leaf area damage (38.99 \%) followed by $A$. versutus $(12.71 \%), S$. ruficollis (11.13\%) and $A$. bengalensis (10.78 \%) however, no much difference was recorded in the actual leaf consumed by $A$. versutus, $S$. ruficollis and $A$. bengalensis. The percent damage caused by $H$. seerata resulted more on leaf compared to the other species both in absence and presence of flower (36.70 and $38.99 \%$ respectively) and it was recorded significantly less by Maladera sp. (3.43 and $0.16 \%$ respectively) and $A$. ferrugenea (7.17 and $0.94 \%$ respectively) (Table 3 ).

\section{Discussion}

\section{Faunal composition of scarabaeids on rose}

The results presented in the paper reveals that thirteen species of scarabaeid beetles were recorded in and around Bangalore district of Karnataka and they are placed under 4 genera under the subfamily: Melolonthinae, 2 genera under the subfamily: Rutelinae and 3 genera under the subfamily: Cetoniinae. Earlier, David and Kalra (1964) reported that species $H$. seerata infestation was more on rose in Hospet, Bellary district of Karnataka. Later, Avasthy (1967) reported the same species in Coimbatore district of Tamil Nadu. Veeresh (1974a) reported as a severe pest on grapevine, guava, and peach in adult stage and found endemic in the district of Bangalore, Mysore and Belgaum of Karnataka. The result of our study revealed that the earlier reports recording the beetles of $H$. seerata was found to be infesting in a large numbers on different host plants such as; rose, tamarind and neem feeding during night on the foliage of plants. Another species of $H$. reynaudi, $H$. rufoflava, $A$. ferruginea, and $S$. ruficollis were found to be feeding more on rose particularly they feed on leaves and flower causing considerable damages by defoliating during April rains. Frey (1971) reported that $H$. reynaudi species derived from Ceylon and adults of this beetles first reported to feed on grapevines (Batra et al., 1973). Jayaram (1997) reported that the adult beetles of $A$. ferruginea found large in numbers feeding on both rose leaves and flowers of Acalypha spp., Guava, tamarind, cinnamon, avocado and ixora in Karnataka. Among the species recorded under Melolonthinae; $A$. rauca and Maladera sp. were found to be feeding extensively more on rose flowers and buds than leaves and it was reported only in Bangalore area of Karnataka. Similar observations were reported by Veeresh $(1977 a, b)$ in Karnataka and by Jayaram (1997) in Tamil Nadu states feeding on rose and other plants like; guava and tamarind.

The beetles of Anomala bengalensis, $A$. versutus, and $A$. bicolor recorded more damage to rose flower than leaves by making irregular holes at G.K.V.K. and Lalbagh. Pruthi and Batra (1960) reported that these species was first appeared on grape in India. Reddy et al., (1978) observed that individuals of $A$. bengalensis feeding on apical buds and tender leaves of mulberry at Hebbal (Bangalore). Fletcher (1914) recorded that $A$. versutus causes damage to rose bushes in South India and Veeresh (1974a) observed that it was commonly defoliating cultivated roses. The damages caused by $A$. bicolor were similar to that the damages caused by $A$. versutus. The incidence of $A$. bicolor was reported the first time damaging roses from South India (Fletcher, 1914). Veeresh (1974a) and Ahmed et al. (1977) reported that this species as a destructive pest to grapevine in Bangalore. All these records are in close agreement with our study revealing that the incidence caused by scarabaeids under subfamily Rutelinae occurred during April and May survey around Bangalore districts of Karnataka. The species of $H$. elegans and $O$. versicolor appeared small number of our study on rose plant and these pests were also reported by Veeresh and Rajanna

Table3. Degree of damage to rose leaf by different species of scarabaeids in absence and presence of flower.

\begin{tabular}{|c|c|c|}
\hline Chafer species & \multicolumn{2}{|c|}{${ }^{*}$ Degree of rose damage } \\
\hline & $\begin{array}{c}\text { In absence } \\
\text { of flower }\end{array}$ & $\begin{array}{c}\text { In presence } \\
\text { of flower }\end{array}$ \\
\hline Holotrichia seerata & $\begin{array}{c}35.88 \\
(36.70)^{a}\end{array}$ & $\begin{array}{c}39.68 \\
(38.99)^{a}\end{array}$ \\
\hline $\begin{array}{l}\text { Anomala } \\
\text { bengalensis }\end{array}$ & $\begin{array}{c}15.48 \\
(22.51)^{b}\end{array}$ & $\begin{array}{c}4.66 \\
(10.78)^{b}\end{array}$ \\
\hline $\begin{array}{l}\text { Schizonycha } \\
\text { ruficollis }\end{array}$ & $\begin{array}{c}3.46 \\
(11.08)^{c}\end{array}$ & $\begin{array}{c}3.78 \\
(11.13)^{b}\end{array}$ \\
\hline Adoretus versutus & $\begin{array}{c}4.7 \\
(11.98)^{c}\end{array}$ & $\begin{array}{c}4.69 \\
(12.7)^{b}\end{array}$ \\
\hline Maladera sp. & $\begin{array}{c}0.38 \\
(3.43)^{d}\end{array}$ & $\begin{array}{c}0.003 \\
(0.16)^{c}\end{array}$ \\
\hline $\begin{array}{l}\text { Apogonia } \\
\text { ferruginea }\end{array}$ & $\begin{array}{c}1.74 \\
(7.17)^{\mathrm{cd}}\end{array}$ & $\begin{array}{c}0.13 \\
(0.94)^{c}\end{array}$ \\
\hline$C D=(5 \%)$ & 5.956 & 5.586 \\
\hline
\end{tabular}

${ }^{*}$ Figures in parentheses are arcsine-transformed values

"Beetles on rose"

by Kumar et al. Indian J.Sci.Technol. 
(1981) causing considerable damages to brinjal plants by feeding on tender shoots, flowers, buds and flowers. These beetles were recorded mostly all the selected locations viz., G.K.V.K, Doddaballapur, Hoskote and Nelamangala. The adults of $P$. cinarea caused less damage to rose plant compare to other beetles during AprilSeptember. Earlier this species was found feeding extensively on brinjal flowers (Tandon et al., 1975; Putaswamy \& Gowda, 1977).

The adult emergence sequences of all the 13 species of scarabaeids recorded on rose around Bangalore districts and it was invariably responded to the onset of monsoon during the month of April. The pattern of adults emergence by different species recorded during the present study agrees with the studies conducted by early workers. All the known species in India have one-year life cycle but differ in the timings of adult emergence period from place to place depending upon the climatic conditions (Avasthy, 1964); Veeresh (1977b). Adults emerge from the soil immediately after dusk on the receipt of first rains during April to July depends upon the area and amount of rain. In south India, normally the adults emerge in April, while in North India it will occur in either May-June or July (David \& Kalra,1964). However, the stray emergency of few small size beetles were recorded during the month of February, corresponding to higher showers after the $1^{\text {st }}$ summer rain, the mixture of smaller and larger sized beetle were found active on rose plant, followed by a larger number of smaller size beetle. The $3^{\text {rd }}$ day after the rain, large number of bigger size beetle started emerging; these was continued for little more than one week. With the peak emergence on $4^{\text {th }}$ and $5^{\text {th }}$ day and continued till the end of September. These findings are in accordance with the studies made by Veeresh and Rajanna (1981) who observed the activity of scarabs throughout the year, activity of some of the species studied were restricted to a limited period in a year.

It is quite interesting to note that though the emergence of the beetles started in the month of April, it continued until the last week of September. In case of $H$. seerata and $A$. bengalensis adult emergence lasted only for three weeks during the month of April and May and ceased to emerge despite there was continuous rain in the season. Similar emergence pattern were recorded by Reddy et al. (1978) who noticed the damage by $A$. bengalensis and $H$. seerata on their host plants immediately after summer rains in April and their activities ceased one week after rain. Kalra and Kulshreshta (1961) opined that first rains in April and May determines the emergence of Holotrichia sp. Veeresh (1977a) reported that more than $90 \%$ of $H$. seerata adults emerged during the week after the first rains in April. Some stray emergence were also noticed in November and December. Garg and Verma (1993) studied bionomics of $A$. dimidiate and observed that beetle started emerging from the soil immediately after heavy rain in June, with the peak emergence recorded in the first fortnight of the month. Whereas, $A$. ferruginea, $A$. rauca, $A$. versutus, and $A$. bicolor started emerging from the last week of April following summer rain, the adult activity continued till the $1^{\text {st }}$ week of September with a peak emergence during April and May. Similar observations were made by Veeresh and Rajanna (1981). In contrast to present study, Veeresh (1974a) reported that peak period of adults emergence of $A$. bicolor was on the $3^{\text {rd }}$ day after each rain and ceased to emerge after the $3^{\text {rd }}$ week of May. The beetles of Maladera sp. was found throughout the season from February to October. The variation in the rainfall appears to have very little influence on the emergence of these species. Though the peak emergence of these species was observed during April and May, and its activity was continued up to the last week of October. Similar trend of emergence of this species were also reported by Veeresh and Rajanna (1981). In case of Cetoniids, $1^{\text {st }}$ emergence was recorded during the month of May and the emergence was continued till the end of October and they were found active on the rose and other alternative host plants during the early hours in the morning and also later in the afternoon. Result of our study is in close agreement with the reports made by Deshpande and Rao (1980) that the activity of $O$. versicolor was continued for nearly two and half months from middle of August to last week of October.

The emergence of adults from the soil was started after dusk at $19.15 \mathrm{~h}$ and continued up to $21.00 \mathrm{~h}$ with recording maximum number of adults $(61 \%)$ emerged between $19.30 \mathrm{~h}$ to $20.00 \mathrm{~h}$. The present findings on the time of adult emergence agree with the observation made by Veeresh (1977a) on H. seerata under Bangalore condition. Yadava et al., (1977) reported that the time of emergence in part of Gujarat and Rajasthan was 19.45 to $20.20 \mathrm{~h}$ and the time of emergence keep extending by 15 to 35 minutes as we move from South to Northern part of the country. Earlier workers reported that temperature, atmospheric humidity and wind velocity influence greatly on the beetle emergence. The light intensity also plays an important role that acts as a triggering mechanism in beetle (Gupta \& Avasthy,1957; Kalra \& Kulshreshta,1961; Rai et al., 1969). The adults of $H$. seerata and $A$. bengalensis caused significantly higher percent of leaf area damage (36.70 and $22.51 \%$ respectively) followed by $A$. versutus $S$. ruficollis (11.98 and $11.08 \%$ respectively) 
However; $A$. ferruginea (7.17 \%) and Maladera sp., $(3.43 \%)$ caused least leaf damage when compared to other species. In general, observations that the flowers and leaves provided to the beetles of $H$. seerata and $A$. bengalensis inflicted higher leaf area damage whereas the beetles of $A$. versutus and $S$. ruficollis did not find any difference in the actual leaf area consumption. Leaf area damage was recorded least in case of $A$. ferruginea and Maladera sp. and they were preferred to fed more on flowers than the other species. The present findings agree with the observations made by Singh (1982) who was reported that there was no significant difference in actual leaf area consumption by $H$. consanguinea, $A$. bengalensis, and Adoretus sp. on rose and ber (Zizyphus mouritiana).

\section{References}

1. Ahmed MA, Tej KS and Dharmaraju E (1977) Cockchafar beetle, Adoretus bicolor Brenske damaging grape vine. Indian J. Entomol. 39(4), 389-391.

2. Avasthy PN (1964) White grubs in sugarcane. Proc. Natl. seminar on plant protection, ICAR, November 4-6, New Delhi.

3. Avasthy PN (1967) Sugarcane pests in India and their control (a review). PANS, 13(2), 111117.

4. Batra RC, Bindra OS and Sohi BS (1973) New record of some chafer beetles as pests of grape vine. Indian J. Entomol. 35(2), 177.

5. David H and Kalra AN (1964) White grub damage to sugarcane crop in Hospet area of Mysore state. Proc. Natl. seminar on plant protection, ICAR, November, 4-6, New Delhi.

6. Deshpande SV and Rao SN (1980) Population fluctuations of the cetoniid beetle (Oxycetonia versicolor). Res. Bull. Marathwada Agri. Univ. 4(7), 90-91.

7. Fletcher TB (1914) Some Indian insects and other animals of importance. Government press, Madras, pp:285-286.

8. Frey G (1971) New Rutelidae and melolonthidae from India and Indo-china (coleoptera). Ent. Arb. Mus., G. Frey. Tutzing Muenchen. 22, 109-133.

9. Garg DK and Verma DV (1993) Bionomics of white grub, Anmala dimidiate in Kumaon Hills, Uttar Pradesh, J. Soil Biol, Ecol. 13(2), 136143.

10. Gowda JV, Gopal A and Sulladmath UV (1984) Studies on the effect of pruning on flowering of roses. The Indian Rose Annual-III, 58-63.

11. Gowda VN and Jayaprasad KV (1997) Floriculture in India, Abstract of papers presented at National seminar on "Flora 97", Bangalore, October 3-5. http://www.indjst.org Vol.2 No 1 (Jan. 2009)

12. Gupta BD and Avasthy PN (1957) First record of the white grub, Lachnosterna consanguinea Blanch. in sugarcane in India. Curr. Sci. 26, 114-115.

13. Jayaram KR (1997) Faunistic studies on the genus Apogonia Kirby (Coleoptera: Scarabaeidae: Melolonthinae) of Karnataka and adjoining states and biology of Apogonia bravus spp. M.Sc. Thesis, University of Agricultural Science, Bangalore, 1-73.

14. Kalra AN and Kulshreshtha JP (1961) Studies on the biology and control of Lachnosterna Consanguinea (Blanch.), a pest of sugarcane in Bihar (India). Bull. Entomol. Res. 52, 577587.

15. Pruthi HS and Batra HN (1960) Some important fruit pests of North-West India. ICAR Bulletin, 80, 48-54.

16. Putaswamy and Gowda V (1977) Record of Chiloloba acuta wied. (Coleotera: Cetonidate) on Solanaceous crops. Curr. Res. 6, 177.

17. Rai BK, Joshi HC, Rathore YK, Dutta SM and Shinde KR (1969) Studies on the bionomics and control of white grubs, Holotrichia consanguinea Blanch. in Lalsat district, Jaipur, Rajasthan. Indian J. Entomol. 31, 132-142.

18. Reddy RV, Gowda LV and Jayaramaiah M (1978) Incidence of chafers (coleoptera: Scarabaeidae) on mulberry, Morus alba L. in Bangalore. White Grubs Newsletters 2(1), 6-7.

19. Singh MP (1982) Studies on the damage and chemical control of chafer beetles on grafted ber (Zizyphus mauritiana Lamk.) cultivars. Entomon. 7(2), 247-250.

20. Tandon $\mathrm{PL}$, Krishnaiah $\mathrm{K}$ and Prasad VG (1975) Protaetia cinerea Kr. (Cetoniinae: Scarabaeidae: Coleoptera) a new insect pest of brinjal from India. Sci. Cult. 41, 288.

21. Veeresh GK (1977a) Studies on the root grubs in Karnataka, with special reference to bionomics and control of Holotrichia seerata F. (Coleoptera: Melolonthinae). UAS Monograph Ser. No. 2, pp. 87.

22. Veeresh GK (1977b) Bionomics and control of white grubs in India. Bill. Ent. 9(6-7), 44-56.

23. Veeresh GK and Rajanna C (1981) Seasonal activity of Scarabaeids as evidenced by light trap catches. Progress in Soil Biology and Ecology. UAS Tech. Ser. 37, 153-158.

24. Yadava CPS, Saxena RC, Mishra RK and Dadheech LN (1977) Population management of white grub, Holotrichia consanguinea $\mathrm{BI}$. In an agro-ecosystem. Indian J. Entmol. 39, 205210. 